\title{
Quality of life assessment in palliative care
}

S ROBIN COHEN

RICHARD SAWATZKY
Introduction

What is quality of life?

Standardized versus individualized measures How can QOL measures support clinical practice?

How do you measure quality of life? Foundations of quality of life assessment validation Quality of life assessment tools

To keep in mind when interpreting QOL scores

The future

References

\section{INTRODUCTION}

The ultimate goal of palliative care is to optimize the quality of life (QOL) of people living with a lifethreatening illness and that of their families. Assessment of QOL is therefore necessary if we are to provide the best care possible and ensure that we are eliminating unnecessary suffering. In this chapter we hope to clarify the concept of QOL at the end of life, identify the questions that you must ask yourself before deciding how to best assess QOL in your particular situation, and discuss the foundations of QOL instrument validation.

\section{WHAT IS QUALITY OF LIFE?}

The WHO Quality of Life working group defined quality of life as “individuals' perceptions of their position in life in the context of the culture and value systems in which they live and in relation to their goals, expectations, standards and concerns" (1). Although this definition is much argued about across and within disciplines, there is general agreement that QOL is a perception. How else can we explain that we may have two people in similar physical situations and close to death, but one judges their QOL to be good and cherishes each day, while the other feels that life is not worth living? Healthcare professions consider QOL an important outcome in many situations. However, a careful look at many of the QOL instruments used in healthcare reveals that health, which the WHO defines as "A state of complete physical, mental and social well-being, and not merely the absence of disease," (2) rather than QOL is being measured (3).

The term health-related QOL, which we and others consider a misnomer $(3,4)$, was developed to broaden the prevalent focus on physical health at the time to also include physical and social functioning, as well as mental health, and/or to exclude from concern domains perceived as unrelated to healthcare, such as spirituality and life satisfaction. Whatever the reason for developing the concept of health-related QOL, it involves limiting the con- 
cept of QOL to certain aspects of the person whose QOL we want to assess. Whole person care is more than simply caring for all aspects of a person, it is also the recognition and understanding that all aspects of the person are interrelated, affecting one another. For this reason we believe that the concept of health-related QOL was created for the convenience of healthcare researchers with good intentions, but it is not a construct that has a match in reality. We cannot separate the physical, psychologic, and social aspects of the person from other essential parts, such as existential wellbeing or spirituality. Furthermore, good QOL is not simply the absence of problems, as it is often defined in health-related QOL measures. Quality of life is determined by the evaluation of both the positive and negative aspects of one's life, and the value or weight you put on each aspect (4-7). The complexity of the concept of QOL, including but not limited to the fact that QOL is a perception of one's position in life, and that contexts, goals, and expectations create that perception, means that QOL is created by the interaction of external circumstances with who the person is. This complexity has implications for optimizing QOL and measuring it. A few examples are given below.

il $Q O L$ is the discrepancy or gap between a person's expectations and their actual situation $(5,8,9)$. This provides us with two means of improving QOL (or decreasing the gap): we can improve the actual situation (e.g. reduce pain) and we can decrease expectations where we cannot improve the actual situation (e.g. desire to retain full physical functional status).

il Response shift or adaptation (5). People have an amazing capacity to adapt to new and even difficult circumstances. This is a powerful way of coping with a difficult situation which is in large part out of your control. Response shift here refers to the situation in which the frame of reference, by which people appraise their quality of life (or other patient-reported outcomes), changes over time. People may have (i) changed their internal standards (called recalibration), (ii) focused on areas in which they are doing better and de-emphasized the importance of areas in which they are not doing well (called reprioritization); or (iii) changed what areas they call to mind when they answer 'How is your QOL?' (called reconceptualization) (5). There is much evidence for this response shift in people with a life-threatening illness, both early in the disease trajectory and at more advanced phases (10-12).

Several studies have shown that ignoring response shift could lead to the inability to detect treatment effects on patient-reported outcomes, such as QOL (13). If we are truly interested in subjective wellbeing, and recognize QOL as a perception, then the fact that response shift or adaptation is affecting our assessment of QOL is not a problem. Response shift could be viewed as a therapeutic outcome. However, when we are determining the effect of an intervention on QOL, then if there is differential response shift in two groups we are comparing, it is often important to know how response shift or adaptation is affecting our assessment of QOL. If the group that received the intervention improves a lot and therefore does not experience a response shift (there is no need to adapt, as the situation has improved), but the group that did not get the intervention had a large response shift over the month that the intervention was being given to the other group (e.g. they deemphasized the importance of the area in which they were not doing well), the two groups may assess their QOL as similar. In the case of the intervention group, it will be because the situation has improved. In the case of the control group, it will be because they have changed their expectations or evaluation of the situation. Both are coping well, but this will hide the effectiveness of the intervention. Supporting this idea of differential response shift, Kvam and colleagues (14) found that response shift plays a greater role in evaluating QOL when the condition of people with multiple myeloma deteriorates than when it improves.

Clearly the possibility of response shift must be taken into account when using QOL assessments in empirical studies and to inform clinical practice. Although further study is needed, significant progress has been made during the past decade to establish reliable statistical and research design approaches to detect, measure, and accommodate response shift in QOL assessment, and to identify people who experience response shift (5). However, this needs to be done with care as each method has advantages and drawbacks. Items that directly measure change (e.g. "Has your social life changed for better or worse?", with responses ranging from "a lot worse" to "a lot better") have been used to help interpret changes in scores on standardized QOL measures. However, response shift has also been shown to affect these direct measures of change, and in different ways depending on whether there is improvement or deterioration (15). Other approaches to re- 
sponse-shift detection rely on statistical methods, including structural equation modelling (16). The choice of method can lead to different results and interpretations. Although the research on response shift detection is in development, palliative care practitioners and researchers need to be aware of the phenomenon and take into account that longitudinal QOL difference scores cannot always be taken at face value.

il Individual differences in the meaning and interpretation of $Q O L$ appraisals. Whereas response shift pertains to a change in the meaning of QOL within individuals over time, differences in the meaning of QOL can also be present between individuals or groups. Such sources of population heterogeneity may be the result of cultural, developmental, gender or personality differences, or because of differences in health and illness experiences or life circumstances. People from different cultural backgrounds and with different life experiences may not interpret the questions that we use to assess QOL in the same way. If ignored, these differences could distort the comparison of QOL scores between individuals or different groups of people. A variety of approaches have been used to identify and accommodate these sources of heterogeneity in patient-reported outcomes and QOL assessment in non-palliative contexts of care $(17,18)$. Although significant advances have been made, we need to better understand the various factors that influence how people, particularly in contexts of palliative care, interpret and respond to questions about their QOL so as to be able to accurately interpret observed differences in QOL assessments between individuals and groups with different backgrounds and life experiences. When assessing QOL in palliative care contexts, it is important to recognize that different people may not ascribe the same meaning and interpretation to the questions used in QOL assessment instruments.

\section{STANDARDIZED VERSUS INDIVIDUALIZED MEASURES}

Standardized measures of QOL have fixed questions and fixed response options. Depending on the questionnaire, answers can be combined to obtain either a score for overall QOL, separate scores for different domains contributing to QOL, or both. Standardized measures can also include items asking people to rate the importance to them of various items or domains. Weighting the responses by the importance assigned to each area or question by each participant has not seemed to change the results when studying the QOL of groups of people, and it therefore is rarely used as it adds to participant burden $(19,20)$. In contrast, individualized QOL measures, such as the Schedule for the Evaluation of Individual Quality of Life (SEIQoL) (21), ask each person to name the areas of their life that are most important to their QOL, how satisfied they are in these areas, and the relative importance of each area named.

Which is best? It depends on the purpose of QOL assessment. While there are individual differences in the meaning and interpretation of QOL assessments, there appears to be sufficient commonality among people in the domains that are generally considered to be important in QOL assessment. For example, most people want to be physically comfortable, be neither depressed nor anxious, be comfortable with their place in the world, etc. Differences in aspects of QOL that are relevant to particular disease populations can be accommodated using standardized disease-specific QOL measures. Nonetheless, standardized measures remain limited in the extent to which they accurately represent individuals' perspectives of their QOL. Individualized measures may therefore be more informative if the purpose is to obtain a measure of an individual's QOL from his or her point of view. However, individualized measures are limited in the extent to which the QOL scores of an individual can be meaningfully compared with those of other people. Thus, to inform clinical practice, some combination of standardized measures (to obtain accurate comparisons with a reference group) and individualized measures (to better understand the meaning of QQL from an individual's point of view) may be most beneficial.

The utilization of QOL measures, some of which are composed of long lists of questions, has been constrained by the time and energy required by people to complete them. Recent methodological advances, including item response theory, item banking and computerized adaptive testing are increasingly being utilized to tailor QOL assessments to individuals, thereby reducing the number of items. Computerized adaptive tests involve administering items based on an individual's responses to previous items such that accurate assessment can be achieved while 
administering just a few items. Thus, different items from a common pool of items (an item bank) are administered to different people to produce a standardized and yet individualized measure. Computerized adaptive tests thus have the advantage achieving accurate assessments with reduced response burden by exposing to individuals to fewer items and by avoiding items that are not relevant or applicable given responses to prior items. Although further research is needed to validate computerized systems, they provide a promising approach to facilitate the utilization of QOL assessment instruments with the least burden to respondents (22).

\section{HOW CAN QOL MEASURES SUPPORT CLINICAL PRACTICE?}

The clinical usefulness of measures of QOL and health status has been tested in many different health care settings $(23,24)$. Despite variation in population and QOL instrument used, giving clinicians the results of a QOL or health status measure completed by their patient just prior to their appointment has been reported to: improve clinician-patient communication $\left(25^{*}\right)$; make the clinician aware of patient problems of which they were otherwise unaware, especially psychological problems $\left(26^{* *}\right)$; and change the care plan $\left(26^{* *}, 27^{*}\right)$. The worse or more complex the patient's condition, the more useful this assessment is for communication and management $\left(28^{*}\right)$. Contrary to clinicians' expectations, interviews in which the instrument information is considered do not take more time $\left(26^{* *}, 29^{* *}\right)$. In palliative care, use of QOL measures in practice aids in detecting patient problems (27) and enhances collaboration among staff $\left(25^{*}\right)$.

\section{HOW DO YOU MEASURE QUALITY OF LIFE?}

Here are some questions you must answer in order to decide how best to assess QOL for your purpose.

1 Am I interested in QOL or rather in a specific contributor to QOL? If the latter (e.g. symptoms), choose a measure of that contributor rather than of QOL (although if you also expect overall QOL to be affected, or QOL in several domains to be affected, you may decide to make these secondary measures).

1 What level of QOL information do I need? You may only want an answer to the question: how is your QOL? However, for many purposes, more detailed information is required, and you will want to know in what domains the person is doing well, and in what domains they are doing poorly. This is especially important in palliative care, where there is an inevitable decline in some areas such as physical wellbeing, but there may be improvement in others such as relationships or existential wellbeing. If you only measure overall QOL over time, it may remain steady despite large changes in different domains. In this case you would select either an instrument that has well-established subscales for different domains (standardized measure with psychometrically sound subscales) or one that allows the person to name the domains important to their QOL and rate their status in each one (individualized measure).

1 Am I interested in comparing groups of people? If yes, do these people have the same disease or different diseases? If you are comparing groups of people with different diseases, do the contributors to QOL differ at the level at which you want to measure QOL? If not, you can use a standardized measure. If the contributors to QOL differ for the two groups at the level you are measuring, the content of a standardized measure will not be equally valid for both groups, and an individualized measure is required for validity. If the contributors to QOL are the same for both groups, do you need to compare at the level of domains (in which case you will need a standardized measure) or at the level of overall QOL (in which case you can choose either an individualized or standardized measure)?

1 Do I need information regarding everyone in the group, or is it acceptable to have only information regarding people capable of completing a questionnaire? If you are in the camp that agrees that QOL is subjective, then it is clear that the person whose QOL is being measured is the best person to rate their own QOL. However, the physical or cognitive status of many palliative care patients precludes them being able to participate in rating their QOL. In this case, proxy measures may be considered. Ideally, someone who 
knows the patient well will rate the patient's QOL on his or her behalf. This may be a member of the staff or the family. However, proxy measures are known to differ from the patient's own ratings, and the difference tends to be greatest for areas that are less concrete (such as existential wellbeing) and where the patient is doing poorly. Many studies have been conducted regarding proxy measures, and the results are inconsistent (30-32). There is no perfect solution in palliative care. You will have to balance the limitations of using proxy measures against the limitation of assessing only those who are well enough to complete a questionnaire.

1 How do I interpret a change in scores? What amount of change in the scale is clinically meaningful to the patient? A statistically significant difference in scores between groups or over time is not necessarily an important one. Some researchers suggest relying on statistically-determined measures of the minimal clinically important difference, which appears to be similar across many QOL studies with different populations and represents about $0.2-0.5$ standard deviations, or 5-10 percent of the scale range (33). Others suggest that anchor-based approaches are more appropriate for determining minimally important differences (34). The ideal is to put the change in scores into a clinically meaningful context (e.g. an improvement in score of 25 percent or 2 points on Psychological Subscale X corresponds to the difference between someone who is clinically depressed and someone who is not really enjoying every day but is not depressed). Sometimes relevant information about score interpretation is available for the instrument you are using. For example, the difference in score between bad, average, and good days is known for the McGill Quality of Life Questionnaire (35). However, if you expect a more subtle change due to your intervention or difference between groups, you may need to be creative and think of ways of asking the person completing the questionnaire to in some way directly rate the importance of the change or indicate what it means clinically (e.g. if measuring physical functioning, what can you do now that you could not do before?)(36-39). In addition, in some circumstances response shift must be taken into account.

1 Do I want to assess QOL to help a particular patient or family caregiver? If so, do I just want an initial assessment, periodic assessments, or do I want to track change in QOL over time? Will the answers to a formal assessment be useful (e.g. the scores), or should I use the QOL instrument as a guide for what to ask, without focusing on the numbers generated? For clinical purposes, QOL measures cannot replace a good, thorough clinical interview. However, QOL measures are helpful as an initial interview guide or to flag areas that need further attention (27, 40-42). Although several studies suggest that QOL measures are useful in clinical practice, much work needs to be done to address barriers to its use in this way (43).

1 How much can I expect my participants to do? Can they complete the questionnaires on their own - do they have the strength, concentration, sight, and reading skills? Or does someone need to read the questions to them? Or is it too long even if read to them? You may want to consider using a short-form or a computerized adaptive test specifically designed to reduce response burden when collecting QOL data. However, further research is needed for such abbreviated instruments to be developed and validated for use in palliative care.

1 Will response shift (adaptation) interfere with my interpretation of the answer, or is the extent to which it occurs irrelevant to my question? If a response shift may greatly influence your conclusions, ideally you would plan some way of measuring the degree of response shift to help you interpret your data (5). Including a change question, or "then-test", may be helpful, but it is important to consider that the same factors that cause response shift may also influence individuals' interpretations and responses to the change question. The then-test may also be influenced by recall bias. Other statistical methods may be required to reliably detect and adjust for response shift if the purpose is to obtain an accurate evaluation of change in QOL over time (e.g., intervention research).

1 If assessing over time, how will I use the data from the different times of data collection? How will I handle the inevitable missing data? There are many established ways of dealing with data missing completely at random. However, in palliative care most of our missing data are not missing at random: usually data are missing because the patient has become too ill to respond or has died, or the patient's deterioration means that the family caregiver no longer has time to complete the questionnaire. There is no perfect solution, but it is an active area of investigation (44). If you are conducting a study we suggest you check the recent literature for new publications on the topic. 
1 What time-frame should the questions refer to? It is important that your questions clearly indicate the time period that people are to consider when answering. QOL measures developed for the general population often refer to the past month, while those that are disease-specific often use a time-frame of the past week. Cohen feels that, because QOL often changes so rapidly near the end of life, a 2-day time-frame is better.

\section{FOUNDATIONS OF QUALITY OF LIFE ASSESSMENT VALIDATION}

Meaningful QOL assessment requires that we understand people's responses to the questions or items that comprise QOL instruments. That is, the use of individual's responses to questions for QOL assessment requires that we understand how these responses relate to the construct (e.g., overall QOL or a particular domain) that we wish to measure. Zumbo (45) discusses four foundational elements of assessment validation theory for establishing such an understanding: validity, psychometrics, utility, and social consequences.

\section{Construct validity}

Any assessment of QOL needs to have construct validity: you need to be assessing QOL, and not some other construct (such as health status). To what extent can you legitimately make inferences about people's QOL based on their responses that are used as assessment indicators of QOL? This includes establishing the various domains that comprise QOL, the "why" and "how" of individual's responses to questions for the assessment of QOL, and understanding the factors that explain QOL (antecedents) and those that are influenced by it (consequences). There is not complete agreement in the literature as to which domains are relevant to the QOL of palliative care patients, but there is a general consensus that QOL comprises at least the physical, psychological, social/relationship, and existential/spiritual domains $(46,47)$. Other domains such as cognitive functioning $(48,49)$, environment (48), and communication have been found to be important in some but not all studies $(46,48)$. The experts as to what content is most relevant to QOL are members of the groups of people whose QOL is to be measured (e.g. patients; family caregivers for their own QOL). Consequently, when assessing QOL in different cultures, validity needs to be established for each culture that differs in ways related to QOL and what is important to it. It is not enough to know that the translation of the scale or interview is accurate and embraces the same concepts, it is necessary to be sure that the interview or questionnaire includes all the relevant content and only relevant content.

\section{Psychometrics}

An important component of establishing assessment validation involves the use of statistics to examine the statistical relationships between QOL and its assessment indicators. This includes the use of factor analysis techniques to determine the dimensional structure of a set of assessment indicators (e.g., to create subscales) and evaluation of the indicators' trustworthiness (test-retest and internal consistency reliability) (50). In addition, modern statistical approaches, such as item response theory and latent variable mixture modelling, are increasingly used to establish assessment scales and evaluate the extent to which assessment properties might be different for different groups of people. A foundational principle is that psychometric evaluation in one population may not be directly applicable to another (e.g. people from a different culture or age group) and should ideally be re-examined.

\section{Utility}

QOL instruments have been created for a variety of purposes. Some instruments are specifically designed to evaluate changes in QOL in different groups (e.g., for use in clinical trials). Other instruments are more appropriate for measuring QOL of larger populations (e.g., for epidemiological studies). Instruments have also been developed for purposes of economic analysis. And some instruments are particularly appropriate for use 
in clinical practice (e.g., to monitor treatment effectiveness or identify particular areas of needs). Instruments are typically developed to maximize the usefulness (utility) and accuracy (sensitivity and specificity) for the particular purpose(s) for which it was developed. When using a QOL instrument, it is therefore important to determine whether this is the most appropriate instrument for your intended purpose.

Any assessment of QOL needs to be acceptable to the person whose QOL is being assessed. The questions must not be distressing. They may raise important feelings and even bring tears, but if these appear to be a welcome opening by the person to discuss important issues with the assessor, then we do not consider it distressing, provided they are given the opportunity to discuss these issues. We and others have informally noted that many palliative care patients find QOL assessments therapeutic. A formal study demonstrates this to be true for family caregivers as well (51). The instrument must also be within the limits of the strength and other capabilities (e.g. reading, or else the opportunity to have it read aloud) of the person whose QOL is being assessed.

\section{Social consequences}

The use of assessment instruments can have both intended and unintended consequences (52). QOL instruments are typically meant to make visible some aspects of QOL from the respondent's point of view so that this information can be used to inform practice, policy, and research. However, the selection of QOL domains that are made visible could have unintended consequences. For example, some QOL instruments include a subscale measuring existential or spiritual domains, whereas others do not. If existential or spiritual domains are important for an individual, then excluding an assessment of this domain could have detrimental consequences. Clinicians may not adequately take existential or spiritual into account when such needs are not made visible. Conversely, instruments that reveal complex existential or spiritual needs may cause clinicians to address these needs without having adequate expertise to do so. As another example, some instruments may reveal aspects of QOL that are important in particular cultural groups. This could lead to the needs of other cultural groups being underrepresented. These types of social consequences must be taken into account when using QOL instruments. Another unintended consequence could occur when people who have experienced response shift are inadvertently penalized for not demonstrating a decline in quality of life scores over time, for example by not being offered an intervention that would alleviate a problem (e.g. pain) so that they don't have to adjust to it.

\section{MEASURING QUALITY OF LIFE THROUGHOUT THE DISEASE TRAJECTORY}

Since palliative care is appropriate from diagnosis on, ideally we would have QOL assessment instruments that are valid throughout the disease trajectory. However, instrument properties such as construct validity and ability to complete the instrument may vary along the trajectory, due to response shift and deteriorating physical status as the disease progresses. For example, women with a recurrence of breast cancer describe their experience and concerns now that the cancer has recurred as quite different from what they were when they were first diagnosed and thought that they could be cured. They describe different kinds of adaptations needed and a reprioritizing of various aspects of their life. They also now grieve for an anticipated future that won't be lived and experience anxiety about the dying process (12). However, other studies suggest that while a re-prioritization may occur at different disease stages, physical, psychological, social, and spiritual/existential well-being are contributors to QOL at all stages (although they may be so named) $(49,53,54)$. It may be that there is more inter-individual variability in what is important to QOL than there is across disease stages.

Many instruments used at earlier stages of the disease and into long-term survivorship tend to focus primarily (although not always exclusively) on physical symptoms and functioning $(55,56)$. Those commonly used further along the disease trajectory tend to measure the social and spiritual/existential domains as well. Instruments commonly used earlier in the disease trajectory tend to be longer than those used at later stages, when the pa- 
tient's capacity to complete the questionnaires becomes a central concern. Few studies have tried to follow patients throughout the disease trajectory, in part because the research questions of interest at different phases tend to differ and in part because of feasibility issues. Another issue that will require study is whether a change in scores has the same meaning at different stages of the disease trajectory. There is evidence that differences in scores are larger when there is deterioration than when there is improvement in QOL $(15,35,38)$.

One solution to the problems of re-prioritization and length of the instrument might be to use an individualized measure of QOL, as the domains will always be important to the respondent. However, when the goal includes assessment of change in one or more particular domains over time, individualized measures cannot be used since the advantage that allows the instrument to account for re-prioritization also means that the domains measured may shift over time.

\section{QUALITY OF LIFE ASSESSMENT TOOLS}

A full review of QOL instruments is beyond the scope of this chapter. Reviews and compendiums of QOL instruments in the palliative care setting are available $(57,58)$. All instruments to date have some limitations. Below we briefly mention a few instruments that have been most commonly used for the assessment of the QOL of patients and family caregivers in palliative care.

\section{Patient QOL}

The McGill Quality of Life Questionnaire (MQOL) $(59,60)$ is the most widely used QOL instrument for studies of people near the end of life and was developed specifically for people with a life-threatening illness. The European Organization for the Research and Treatment of Cancer Quality of Life Questionnaire - Cancer, 30 items (EORTC QLQ-C30)(56) and Functional Assessment of Cancer Therapy- General (FACT-G, later called FACITG)(53) are widely used in studies of people undergoing anti-cancer treatment, the population for which they were designed. In palliative care studies of the outcome of interventions aimed at physical symptom management, they are the most often used QOL instruments, often with add-on modules for different cancer sites or diseases. To make them more suitable for palliative care, the EORTC has developed a short form (EORTC PAL) (61) and an add-on module has been developed for the FACT to create the FACIT-PAL (62), although neither has yet been widely used. While standardized QOL instruments developed for people at the end of life measure the existential/spiritual domain, with MQOL having a validated existential well-being subscale, instruments developed for use primarily with people undergoing anti-cancer treatment often do not. Because of the increasing recognition of the spiritual domain as important to QOL, modules measuring this aspect of QOL have been developed for the FACIT (63) and the EORTC has developed a stand-alone measure (64). The FACIT spirituality module is being used fairly frequently for research where spirituality is an important outcome, on its own or in conjunction with the FACIT-G. QUAL-E is another QOL instrument developed for people at the end of life (65). The individualized QOL instrument Schedule for Evaluation of Individualized Quality of Life - Direct Weighting (SEIQoL-DW) (66) can be used for patients or family caregivers. Interest in QOL assessment for people with end-stage diseases other than cancer is more recent. Most use the SF-36 (67), even though it is a health status measure, or disease-specific measures, although MQOL has been used for some, especially ALS (68).

Since palliative care is much less developed for life-threatening illnesses other than cancer, there is a concomitant relative lack of QOL studies in those areas, although these are increasing. Unfortunately, the same mistake regarding content validity is often made as when studies of "QOL" in cancer first began; the tendency to focus mainly on physical symptoms and functioning or health (67), rather than the broader concept of QOL, is being repeated with assessment of QOL for some other diseases (e.g. COPD, heart failure; $(55,69)$ ). Fortunately, there are exceptions $(68,70)$. We hope that a careful evaluation of the construct validity of QOL measures for all lifethreatening illnesses will be carried out in the near future.

\section{Family caregiver QOL}


There has been much less research regarding the QOL of family caregivers. The Caregiver Quality of LifeCancer instrument (71), Caregiver Quality of Life Index (72), and Quality of Life in Life-Threatening llnessCaregiver (73) have all been developed to measure the QOL of family caregivers of people at the end of life. More experience in their use is needed to understand their strengths and weaknesses.

\section{TO KEEP IN MIND WHEN INTERPRETING QOL SCORES}

Just as with many medical tests, there are conditions that may invalidate QOL scores even from well-developed instruments or make them difficult to interpret. These cautions apply especially if QOL scores are being used to inform care plans, but also for research.

- Items may not be interpreted as intended and different people may not interpret items in the same way.

- Construct validity is an important consideration as different instruments may not be measuring the same QOL construct (e.g. some instruments might focus predominantly on symptoms and functioning whereas others include questions pertaining to a broader understanding of QOL).

- Although some instruments use items that need to be reverse scored (i.e. the best QOL is not always at the same end of the rating scale, in order to avoid the respondent developing a habit of checking off the same answer without carefully considering the item), this can be confusing, resulting in the wrong answer being selected. This is likely especially true when fatigue or medication decreases cognitive acuity.

- Response shift needs to be considered.

If possible when there are scores that are counter-intuitive, it is best to speak with the respondent to determine their understanding of the item and their intended answer. Studies can be designed as mixed-methods studies, with a qualitative component intended to inform interpretation of the QOL instrument scores.

\section{THE FUTURE}

Despite the need to interpret QOL scores carefully, QOL assessment has brought renewed focus in health care to what is important to people whose QOL is in jeopardy. We look forward to a future where patients and family caregivers will be understood and described not only in terms of their disease and symptom status, but also in terms of their QOL. Only then can palliative care really be addressing whole person care.

\section{Key learning points}

1 Improving QOL is the main goal of palliative care, therefore assessing it is critical if we want to understand the extent to which we are achieving our goals.

1 QOL assessment provides an Assessment of the whole person. QOL is a perception. It is not a specific set of external circumstances, but rather the interaction of the person with external and internal circumstances.

1 The 'best' way of assessing QOL will depend on your purpose in assessing it.

1 There is no perfect way to assess QOL in palliative care. Choose the best way, or combination of ways, and be aware of its strengths and limitations. 


\section{REFERENCES}

1. WHO. The World Health Organization Quality of Life Assessment (WHOQOL): Position paper from the World Health Organization. Social Science \& Medicine. 1995;41(10):1403-9.

2. WHO. WHO Definition of Health. [cited 2012 May 29]; Available from: http://www.who.int/about/definition/en/print.html.

- 3. Michalos AC. Social indicators research and health-related quality of life research. Social Indicators Research. 2004;65(1):27-72.

4. Hunt SM. The problem of quality of life. Quality of Life Research. 1997;6(3).

5. Schwartz CE. Applications of response shift theory and methods to participation measurement: A brief history of a young field. Archives of Physical Medicine and Rehabilitation. 2010;91(9, Supplement):S38-S43.

- 6. Sprangers MAG, Schwartz CE. Integrating response shift into health-related quality of life research: a theoretical model. Social Science \& Medicine. 1999;48(11):1507-15.

7. Folkman S. Positive psychological states and coping with severe stress. Social Science \& Medicine. 1997;45(8):1207-21. Epub 1997/09/25.

- 8. Cantril H. The Pattern of Human Concerns: New Brunswick, NJ, Rutgers U. P; 1966.

- 9. Campbell A, Converse PE, Rodgers WL. The Quality of American Life: Perceptions, Evaluations, and Satisfactions: Russell Sage Foundation; 1976.

10. Kreitler S, Chaitchik S, Rapoport Y, Kreitler H, Algor R. Life satisfaction and health in cancer patients, orthopedic patients and healthy individuals. Social Science \& Medicine. 1993;36(4):547-56.

11. Neuman HB, Park J, Fuzesi S, Temple LK. Rectal cancer patients' quality of life with a temporary stoma: shifting perspectives. Dis Colon Rectum. 2012;55(11):1117-24. Epub 2012/10/10.

12. Kenne Sarenmalm E, Thoren-Jonsson AL, Gaston-Johansson F, Ohlen J. Making sense of living under the shadow of death: adjusting to a recurrent breast cancer illness. Qual Health Res. 2009;19(8):1116-30. Epub 2009/07/30.

13. Schwartz C, Bode R, Repucci N, Becker J, Sprangers M, Fayers P. The clinical significance of adaptation to changing health: A meta-analysis of response shift. Quality of Life Research. 2006;15(9):1533-50.

14. Kvam AK, Wisloff F, Fayers PM. Minimal important differences and response shift in health-related quality of life; a longitudinal study in patients with multiple myeloma. Health \& Quality of Life Outcomes. 2010;8:79.

15. Taminiau-Bloem EF, Van Zuuren FJ, Visser MR, Tishelman C, Schwartz CE, Koeneman MA, et al. Opening the black box of cancer patients' quality-of-life change assessments: a think-aloud study examining the cognitive processes underlying responses to transition items. Psychol Health. 2011;26(11):1414-28. Epub 2011/07/09.

$\Delta$ 16. Schwartz CE, Ahmed S, Sawatzky R, Sajobi T, Mayo N, Finkelstein J, et al. Guidelines for secondary analysis in search of response shift. Qual Life Res. 2013. Epub 2013/04/11.

17. Sawatzky R, Ratner P, Johnson J, Kopec J, Zumbo B. Sample heterogeneity and the measurement structure of the multidimensional students' life satisfaction scale. Social Indicators Research. 2009;94(2):273-96.

18. Sawatzky R, Ratner P, Kopec J, Zumbo B. Latent variable mixture models: a promising approach for the validation of patient reported outcomes. Quality of Life Research. 2012;21(4):637-50.

19. Skevington SM, O'Connell KA. Can we identify the poorest quality of life? Assessing the importance of quality of life using the WHOQOL-100. Quality of Life Research. 2004;13(1):23-34.

20. Cella D. The Functional Assessment of Cancer Therapy-Anemia (FACT-An) Scale: a new tool for the assessment of outcomes in cancer anemia and fatigue. Seminars in hematology. 1997;34(3 Suppl 2):13-9. 
21. McGee HM, O'Boyle CA, Hickey A, O'Malley K, Joyce C. Assessing the quality of life of the individual: the SEIQoL with a healthy and a gastroenterology unit population. Psychological Medicine. 1991;21(03):749-59.

22. Garcia SF, Cella D, Clauser SB, Flynn KE, Lad T, Lai J-S, et al. Standardizing patient-reported outcomes assessment in cancer clinical trials: A patient-reported outcomes measurement information system initiative. Journal of Clinical Oncology. 2007;25(32):5106-12.

23. Greenhalgh J. The applications of PROs in clinical practice: what are they, do they work, and why? Qual Life Res. 2009;18(1):115-23. Epub 2008/12/24.

24. Valderas JM, Alonso J. Patient reported outcome measures: a model-based classification system for research and clinical practice. Quality of Life Research. 2008;17(9):1125-35. Epub 2008/10/07.

25. Schwartz CE, Merriman MP, Reed G, Byock I. Evaluation of the Missoula-VITAS Quality of Life Index - Revised: Research tool or clinical tool? Journal of Palliative Medicine. 2005;8(1):121-35.

26. Velikova G, Booth L, Smith AB, Brown PM, Lynch P, Brown JM, et al. Measuring quality of life in routine oncology practice improves communication and patient well-being: A randomized controlled trial. Journal of Clinical Oncology. 2004;22(4):714-24.

27. Eischens MJ, Elliott BA, Elliott TE. Two hospice quality of life surveys: A comparison. American Journal of Hospice and Palliative Medicine. 1998;15(3):143-8.

28. Wagner AK, Ehrenberg BL, Tran TA, Bungay KM, Cynn DJ, Rogers WH. Patient-based health status measurement in clinical practice: a study of its impact on epilepsy patients' care. Quality of Life Research. 1997;6(4):329-41.

29. Detmar SB, Muller MJ, Schornagel JH, Wever LDV, Aaronson NK. Health-related quality-of-life assessments and patientphysician communication: A randomized controlled trial. JAMA: Journal of the American Medical Association. 2002;288(23):302734.

30. Jones JM, McPherson CJ, Zimmermann C, Rodin G, Le LW, Cohen SR. Assessing agreement between terminally ill cancer patients' reports of their quality of life and family caregiver and palliative care physician proxy ratings. Journal of Pain and Symptom Management. 2011;42(3):354-65.

31. Horton R. Differences in assessment of symptoms and quality of life between patients with advanced cancer and their specialist palliative care nurses in a home care setting. Palliative Medicine. 2002;16(6):488-94.

32. McPherson CJ, Addington-Hall JM. Judging the quality of care at the end of life: can proxies provide reliable information? Social Science \& Medicine. 2003;56(1):95-109.

33. Norman GR, Sloan JA, Wyrwich KW. Interpretation of changes in health-related quality of life: The remarkable universality of half a standard deviation. Medical Care. 2003;41(5):582-92.

34. Hays RD, Farivar SS, Liu H. Approaches and recommendations for estimating minimally important differences for healthrelated quality of life measures. COPD. 2005;2(1):63-7. Epub 2006/12/02.

35. Cohen SR, Mount BM. Living with cancer: "Good" days and "bad" days-What produces them? Cancer. 2000;89(8):1854-

65.

36. Osoba D, Rodrigues G, Myles J, Zee B, Pater J. Interpreting the significance of changes in health-related quality-of-life scores. Journal of Clinical Oncology. 1998;16(1):139-44.

37. Cella D, Bullinger M, Scott C, Barofsky I. Group vs individual approaches to understanding the clinical significance of differences or changes in quality of life. Mayo Clinic Proceedings. 2002;77(4):384-92.

38. Cella D, Hahn EA, Dineen K. Meaningful change in cancer-specific quality of life scores: Differences between improvement and worsening. Quality of Life Research. 2002;11(3):207-21.

39. Guyatt GHGH, Osoba DD, Wu AWAW, Wyrwich KWKW, Norman GRGR. Methods to explain the clinical significance of health status measures. Mayo Clinic Proceedings Mayo Clinic. 2002;77(4):371-83.

40. Finlay IG, Pratheepawanit N, Salek MS. Monitoring self-reported quality-of-life among patients attending a palliative medicine outpatient clinic. Palliative Medicine. 2003;17(1):83-4.

41. Higginson IJ, Alison JC. Measuring quality of life: Using quality of life measures in the clinical setting. BMJ: British Medical Journal. 2001;322(7297):1297-300. 
42. Hughes R, Aspinal F, Addington-Hall J, Chidgey J, Drescher U, Dunckley M, et al. Professionals' views and experiences of using outcome measures in palliative care. International Journal of Palliative Nursing. 2003;9(6):234-8.

43. Hughes R, Aspinal F, Addington-Hall JM, Dunckley M, Faull C, Higginson I. It just didn't work: The realities of quality assessment in the English health care context. International Journal of Nursing Studies. 2004;41(7):705-12.

44. Fairclough DL. Design and Analysis of Quality of Life Studies in Clinical Trials: Chapman \& Hall/CRC; 2010.

45. Zumbo BD. Validity as contextualized and pragmatic explanation, and its implications for validation practice. In: Lissitz RW, editor. The concept of validity: Revisions, new directions and applications. Charlotte, NC: Information Age Publishing; 2009. p. 65-82.

46. Cohen SR. Assessing Quality of Life in Palliative Care. In: In: Portenoy R, \& Bruera, E., eds., editor. Issues in palliative care research. New York: Oxford University Press; 2003. p. 231-41.

47. Ferrans CE. Definitions and Conceptual Models of Quality of Life. In: Lipscomb J, Gotay CC, Snyder C, editors. Outcomes assessment in cancer: Measures, methods, and applications. Cambridge, NY: Cambridge University Press; 2005. p. 14-30.

48. Cohen SR, Leis A. What determines the quality of life of terminally ill patients from their own perspective? Journal of Palliative Care. 2002;18(1):48-58.

49. Padilla G, Ferrell B, Grant M, Rhiner M. Defining the content domain of quality of life for cancer patients with pain. Cancer Nursing. 1990;13(2):108.

50. Fayers P, Machin D. Quality of Life: The Assessment, Analysis and Interpretation of Patient-Reported Outcomes. Chichester, West Sussex, England: John Wiley \& Sons; 2007.

51. Hudson P. The experience of research participation for family caregivers of palliative care cancer patients. International Journal of Palliative Nursing. 2003;9(3):120-3.

- 52. Messick S. Validity of psychological assessment: Validation of inferences from persons' responses and performances as scientific inquiry into score meaning. American Psychologist. 1995;50(9):741-9.

53. Cella DF, Tulsky DS, Gray G, Sarafian B, Linn E, Bonomi A, et al. The Functional Assessment of Cancer Therapy scale: development and validation of the general measure. J Clin Oncol. 1993;11(3):570-9. Epub 1993/03/01.

54. Ferrell B, Grant M, Funk B, Garcia N, Otis-Green S, Schaffner M. Quality of life in breast cancer. Cancer practice. 1996;4(6):331.

55. Habraken JM, van der Wal WM, Ter Riet G, Weersink EJ, Toben F, Bindels PJ. Health-related quality of life and functional status in end-stage COPD: a longitudinal study. European Respiratory Journal. 2011;37(2):280-8.

56. Aaronson NK, Ahmedzai S, Bergman B, Bullinger M, Cull A, Duez NJ, et al. The European Organization for Research and Treatment of Cancer QLQ-C30: a quality-of-life instrument for use in international clinical trials in oncology. Journal of the National Cancer Institute. 1993;85(5):365-76.

57. Albers G, Echteld MA, de Vet HC, Onwuteaka-Philipsen BD, van der Linden MH, Deliens L. Evaluation of quality-of-life measures for use in palliative care: a systematic review. Palliative Medicine. 2010;24(1):17-37.

58. Research Trust M. Patient-reported outcomes and quality of life instruments database. MAPI Research Trust; 2012 [cited 2012 June 4]; Available from: www.proqolid.org.

59. Cohen SR, Mount BM, Bruera E, Provost M, Rowe J, Tong K. Validity of the McGill Quality of Life Questionnaire in the palliative care setting: a multi-centre Canadian study demonstrating the importance of the existential domain. Palliative Medicine. 1997;11(1):3-20.

60. Cohen SR, Mount BM, Tomas JJN, Mount LF. Existential well-being is an important determinant of quality of life: Evidence from the McGill Quality of Life Questionnaire. Cancer. 1996;77(3):576-86.

61. Groenvold M, Petersen MA, Aaronson NK, Arraras JI, Blazeby JM, Bottomley A, et al. The development of the EORTC QLQ-C15-PAL: A shortened questionnaire for cancer patients in palliative care. European Journal of Cancer. 2006;42(1):55-64.

62. Greisinger AJ, Lorimor RJ, Aday LA, Winn RJ, Baile WF. Terminally ill cancer patients. Their most important concerns. Cancer Practice. 1997;5(3):147-54. 
63. Peterman AH, Fitchett G, Brady MJ, Hernandez L, Cella D. Measuring spiritual well-being in people with cancer: the functional assessment of chronic illness therapy--Spiritual Well-being Scale (FACIT-Sp). Annals of Behavioral Medicine. 2002;24(1):4958.

64. Vivat B, Young T, Efficace F, Sigurdadottir V, Arraras JI, Asgeirsdottir GH, et al. Cross-cultural development of the EORTC QLQ-SWB36: a stand-alone measure of spiritual wellbeing for palliative care patients with cancer. Palliat Med. 2013;27(5):457-69. Epub 2012/07/31.

65. Steinhauser KE, Bosworth HB, Clipp EC, McNeilly M, Christakis NA, Parker J, et al. Initial assessment of a new instrument to measure quality of life at the end of life. Journal of Palliative Medicine. 2002;5(6):829-41.

66. Waldron D, O'Boyle CA, Kearney M, Moriarty M, Carney D. Quality-of-life measurement in advanced cancer: Assessing the individual. Journal of Clinical Oncology. 1999;17(11):3603-11.

67. Ware JE, Jr., Sherbourne CD. The MOS 36-Item Short-Form Health Survey (SF-36): I. Conceptual framework and item selection. Medical Care. 1992;30(6):473-83.

68. Robbins RA, Simmons Z, Bremer BA, Walsh SM, Fischer S. Quality of life in ALS is maintained as physical function declines. Neurology. 2001;56(4):442-4.

69. Mulligan K, Mehta PA, Fteropoulli T, Dubrey SW, McIntyre HF, McDonagh TA, et al. Newly diagnosed heart failure: Change in quality of life, mood, and illness beliefs in the first 6 months after diagnosis. British Journal of Health Psychology. 2012;17(3):447-62.

70. Grady KL, de Leon CFM, Kozak AT, Cursio JF, Richardson D, Avery E, et al. Does self-management counseling in patients with heart failure improve quality of life? Findings from the Heart Failure Adherence and Retention Trial (HART). Quality of life Research. 2013:1-8.

71. Weitzner MA, Jacobsen PB, Wagner H, Friedland J, Cox C. The Caregiver Quality of Life Index-Cancer (CQOLC) scale: development and validation of an instrument to measure quality of life of the family caregiver of patients with cancer. Quality of Life Research. 1999;8(1):55-63.

72. McMillan SC, Mahon M. The impact of hospice services on the quality of life of primary caregivers. Oncology Nursing Forum. 1994;21(7):1189-95.

73. Cohen SR, Leis A, Porterfield P, Hsu D, Kuhl D, Charbonneau C, et al. QOLLTI-F: A measure of the QOL of family caregivers of palliative care patients. Quality of Life Research. 2001:231. 